\title{
Del liberalismo revolucionario al liberalismo post-revolucionario en España El triunfo final del camino inglés
}

\author{
ÁNGELES LARIO \\ UNED*
}

\section{From revolationary Liberalism to post-revolutionary Liberalism. On the historical origin of «Presidentialism» and «Parlamentarism»}

\section{RESUMEN}

En este artículo se trata del cambio político producido en España desde el modelo liberal revolucionario de 1812 al modelo post-revolucionario, moderado, introducido a la mueite de Fernando VII. España realiza este tránsito al pleno estilo europeo de la época. El modelo de 1812 fue el revolucionario, con separación estricta de poderes, al modo puramente constitucional que había establecido Locke y que habia introducido Montesquieu en el Continente. Esta separación estricta de poderes no funcionó en la monarquia, aunque si lo habia hecho en la República de los Estados Unidos de Norteamérica, con un Ejecutivo elegible, con la misma legitimidad que el Legislativo. Fue precisamente la diferente legitimidad de los dos poderes en las Monarquias, lo que hizo necesario buscar en el gobierno parlamentario el medio de hacer convivir la vieja institución con el Liberalismo; de ese modo se podría aumentar el poder Ejecutivo sin sufrir de nuevo el peligro del despotismo monárquico. Para ello, se volvió la vista hacia la práctica inglesa, que ha-

\begin{abstract}
In this article, I study the political change in Spain, from the revolutionary liberalism of 1812 , to the moderate liberalism when Fernando VII died. Spain passes to the new model as it was very common in Europe. The 1812 model was the revolutionary, with strict separation of powers, in the purely constitutional way established by Locke and introduced by Montesquieu in the Continent. This strict separation of powers worked in the U.S. with an eligible Executive with the same renewed legitimity as the Legislative; it did'nt work in the Monarchy where Executive and Legislative have different legitimity. This different legitimity of powers made it necessary to search in the parliamentary System, the way to adapt the Monarchy to the Liberalism. Then, it was posible to grow the Executive power without running the risk of despotism. Therefore they looked at the English way, where the Secretaries of the King had become an effective power, the Cabjnet, the elective part of the Executive which could be strengthened as it came out of the Parliament itself.
\end{abstract}

* En el marco del proyecto de investigación 06/HSE/0234/2004, que dirijo dentro del Programa "Ramón y Cajal". 
bia convertido a los Secretarios del Rey en un órgano de poder efectivo, el Gabine. te, la parte electiva del Ejecutivo que si se podía fortalecer, puesto que salía del propio Parlamento.
KEY WORDS:

Liberalism, parlamentary government, Constitutions of 1812, 1837, 1845.

PALABRAS CLAVE:

Liberalismo, gobierno parlamentario, Constituciones de 1812, 1837, 1845.

\section{EL INTENTO DE UNA REVOLUCIÓN PROPIA. EL PRIMER CAMINO INGLÉS Y LA “CONSTITUCIÓN HISTÓRICA»}

"Vejamos a Inglaterra, esse governo sempre citado, sempre imitado por quasi todos os povos que querem ser livres. A Inglaterra passou de um estado quasi anormal, porque excessivamente aristocratico, a uma existencia muito mais regular. O principio democratico tomou o seu logar na Constituição ingleza ha cinco annos a esta parte. E todavia as fórmas exteriores de civilidade, e cumprimento, são tão excessivamente monarchicas, que muitas vezes repugnam a nossos ouvidos ciosos, e recusariam nossas bocas livres pronuncia-las. Mas o equilibrio é perfeito. A corôa respeitada, e rodeada de cortejos e homenagens, é todavia impotente para mal fazer». Diario de Sesiones de la Sesión Extraordinaria de 1837. Lisboa. Sr. Almeida Garrett, 24 de Abril de 1837.

La referencia al camino inglés, como no podía ser menos, alude al modelo moderado de gobierno parlamentario que había nacido y se estaba desarrollando en la monarquía inglesa tras su revolución del XVII ( $y$ que no deja de tenerse en cuenta siquiera en los procesos constituyentes del $x x$, como es el caso italiano de 1946-471). En España, los primeros intentos de inclinar la balanza en un sentido "parlamentario", se encuentran en los mismos momentos en que se gesta la revolución política, en medio de la guerra contra los franceses. La influencia inglesa fue evidente en estos primeros momentos en Jovellanos, principal protagonista en la Junta Central en 1809-10².

En Jovellanos la solución política pasaba por la tradición española de Cortes con Rey, y por ello veía en el caso inglés, que partió de los mismos principios en su revolución del XVII frente al absolutismo, el modelo a seguir. Sin embargo, Adolfo Posada advierte que "de haber realizado los legisladores de Cádiz una restauración o resurrección - artificial tenía que ser- de las formas y fórmulas políticas tradicionales, anteriores al absolutismo monárquico, la Constitución de 1812 habría galvanizado una

1 VARELa SUANzes, J.: "Sistema de Gobierno y partidos políticos en el pensamiento constitucional británico durante el ultimo tercio del siglo xVIII (de Blackstone a Paley)", en Revista Electrónica de Historia Constitucional, n. ${ }^{\circ}$ 1, 2000. Para el caso italiano, por ejemplo NITTI el 23 de octubre de 1947: “Nel Paese da cui vengono le forme costituzionali, l'Inghilterra,...", en Archivio Storico. Camera dei Deputati: La Costituzione della Repubblica nei lavori preparatori della Assemblea Costituente (AS,CD).

2 Lo muestra MORENO ALONSO: La forja del Liberalismo en España. Los amigos españoles de Lord Holland 1793-1840. Congreso de los Diputados, Madrid 1997. p. 116. 
España vieja mucho más artificiosa y de prestado...». Pero quizá haya que poner ciertos reparos a este eminente autor porque acto seguido reconoce, sin embargo, que "salvo Inglaterra -y de otro modo, y con otras explicaciones los Estados Unidos- todos los pueblos que se han constitucionalizado lo han hecho mediante "imitaciones", mejor o peor interpretadas y asimiladas" ${ }^{3}$. Y es que, mientras reconoce la originalidad inglesa, niega a "los Jovellanos" la bondad de su resolución para seguir el mismo camino, entre otras cosas porque no reconoce en el caso inglés lo que ellos mismos mantuvieron como justificación de su revolución: la vuelta a los antiguos fueros y libertades de los gobernados. Todavía en la España revolucionaria y en el caso de Jovellanos, imitar lo inglés era seguir su mismo camino para hacer una revolución propia, lo que, como sabemos, se vio alterado por la forma y las circunstancias en que fueron convocadas las Cortes de Cádiz, aunque no impidió una fuerte presencia de la historia y la tradición española en las discusiones constituyentes.

El influjo inglés en el momento revolucionario se traduce en el intento de cortar el camino de la revolución francesa, y de mostrar que frente a la revolución y el jacobinismo debia imperar la libertad; frente a las reformas violentas y repentinas, las mejoras paulatinas a través de la libertad de prensa y -debería haber sido también- la libertad religiosa que, sin embargo, será justamente lo que no se incorpore en 1812: la secularización, la religión como culto privado, que acompañó a la revolución en Inglaterra, en Francia o en los Estados Unidos ${ }^{4}$. Jovellanos personifica en España y en el momento de la revolución este primer camino inglés, con el "esfuerzo realmente asombroso para contener los avances revolucionarios", y "su preocupación e insistencia por dejar acabado... un sistema moderado de gobierno... una copia del sistema constitucional inglés" ${ }^{5}$. Era un terreno abonado, por otra parte, pues se produce en un contexto de guerra contra Francia, a to que hay que sumar la merma de su influjo tras la Revolución y las guerras de la Convención de 1893 (ya Feijoo recogía que hasta los franceses reconocían «la ventaja del espíritu filosófico ingles"). Rodríguez Aranda dejó reflejada la huella de Locke "desde Feijoo a Jovellanos o desde Martínez Marina a Quintana». El propio Godoy en sus Memorias se atribuye la introducción de Locke y Newton en las cátedras españolas. Si nos adelantamos más en el tiempo, al estudiar a los constitucionalistas del XIX y los discursos de los políticos de la Restauración, se percibe igualmente de un modo claro que el constitucionalismo inglés, es «punto de referencia fundamental para todo el liberalismo europeo" ${ }^{6}$. Ciertamente, en las discusiones de los consti-

${ }^{3}$ Posada, A.: La reforma constitucional, Madrid 1931, pg. 63-64.

4 Jourdan, A.: La Révolution, une exception française?, Flammarion, Paris 2004, pp.304-305. PorTILLO VALDÉS, J. M.: Revolución de nación. Origenes de la cultura constitucional en España, 1780-1812, CEPyC, Madrid, 2000, cap. I.

${ }_{5}$ ARtola, M.: La España de Fernando VII, Espasa Calpe, Madrid, 1999, p. 323. Sobre el sentido de reforma de las Leyes Fundamentales en Jovellanos, y su admiración por la «excelente constitución inglesa”: Fernández SaRAsola, 1.: Poder y libertad: los origenes de la responsabilidad del Ejecutivo en España (1808-1823). Centro de Estudios Políticos y Constitucionales, Madrid, 2001; especialmente p. 303-306.

${ }_{6}$ Moreno Alonso: La forja del Liberalismo, cit., p. 49. Lafio, A.: El Rey, piloto sin brújula, Biblioteca Nueva, Madrid 1999. 
tuyentes franceses de 1789 , Inglaterra está presente constantemente, pero en muchos casos para recordar los defectos de su sistema; mayoritariamente se reconoce su aportación a la libertad y la superioridad de su espíritu público, asentado durante ya mucho tiempo, pero eso les sirve para defender que las leyes francesas deban ser más perfectas para compensar esa diferencia? ${ }^{7}$.

El camino inglés implica convivencia entre los poderes, y por ello no se olvida Holland de señalar a sus amigos españoles la equivocación de Montesquieu, que difundió el modelo inglés por el continente, cuando creyó ver en él una separación estricta de poderes; efectivamente, dice, la Cámara de los Comunes, «por el derecho que goza de disponer de los medios y arbitrios, pudiera ganar toda la máquina del Estado si se empeñara en hacerlo», pero el equilibrio procedía del influjo "real y efectivo que la Corona y la Cámara de los Pares tienen en (ella)»8.

En el momento de la convocatoria de Cortes se trató de convocarlas al modo antiguo, en tres brazos; pero ya en enero de 1810 se pensó en dos Cámaras, aunque ampliando el número de electores municipales y «añadiendo otros tantos representantes libremente elegidos por el vecindario", que fueran únicamente electores y no elegibles. Las Cortes debían estar presididas por la Regencia, y las leyes debían ser aprobadas por ambas Cámaras y sancionadas por la Regencia, que también podía disolver las Cortes ${ }^{9}$ : esta era la materialización de la idea de Jovellanos de que las Cortes deberían quedar «acomodadas a las luces del siglo y a los muchos mandamientos que se han hecho desde el siglo dieciséis, y muy aumentadas en el número de sus vocales». A esa búsqueda en el armario de la historia de los elementos necesarios para componer una nueva figura, se le ha denominado con extraordinario éxito «invención de la tradición», pero ya Jovellanos habia hablado de "acomodación" a la actualidad de elementos preexistentes.

En Jovellanos -o el propio Alcalá Galiano-, el conocimiento del proceso revolucionario francés, y las reflexiones sobre el mismo de Burke que según Varela ${ }^{10}$ ya conocía en 1795, consagran su horror a la ruptura violenta. Pero no pudo escapar de la contradicción de situarse en medio de una tendencia reformista que, a su vez, abría el camino a un proceso revolucionario. En la misma Inglaterra, siempre tomada como ejemplo de moderación y reformas paulatinas, decía Guizot que no se hubiera podido llegar a la revolución moderada de la Gloriosa de no haber pasado por la revolución radical de $1640-49^{11}$. Y es que, lo que caracterizó la

7 Rabaud de Saint-Etienne, el 4 de septiembre de 1789. Id. Gregoire. Id. Alexandre de Lameth (cita, p.ej. a De Lolme). Id. Mirabeau el 1 de septiembre: «los ingleses lo han hecho todo". Sobre la necesidad de superar a los ingleses en las leyes: M. De Castellane, 3 de septiembre: Archives Parlamentaires. Asemblée nationale. Paris (APP.AN).

8 Moreno Alonso, cit., pp. 262-263. Puede verse también Sánchez Garcia, R.: Alcalá Galiano y el liberalismo español, CEPyC, Madrid, 2005, «la formación de un liberal», pp. 64-66.

9 ARTOLA, cit., 319-320, 323.

10 VARELA, J.: Jovellanos, Alianza Universidad, Madrid 1988, p. 243.

11 JOURDAN, cit., p. 303-304. LARIO, "La Monarquía Constitucional. Teoría y práctica política", en J. Tusell, A. LARio, F. Portero (eds), La Corona en la historia de España, Biblioteca Nueva, Madrid, 2003, pp. 106-111. 
revolución española fue la transferencia de hecho de la soberanía a nuevas instituciones surgidas del levantamiento popular, a que dio lugar la defensa frente a la invasión francesa de la que, inmediatamente, se denominará nación. Por ello no iba a resultar fácil mantener la soberanía del Rey ausente en medio de un proceso de defensa y constitución de la nación por las Cortes.

\section{LA PRESENCIA DE LA HISTORIA EN LA CORTES DE CÁDIZ}

Sin embargo, las discusiones constituyentes en Cádiz sí mostraron esa impronta histórica que defendía Jovellanos. Quizá como nunca en Cádiz se acomodó la tradición a las nuevas necesidades. La misma existencia de una comisión para recopilar y revisar las antiguas constituciones y fueros -donde destacó la figura ya venerable del catalán Antoni de Capmany-, constantemente manejadas $y$ tenidas en cuenta por los constituyentes, las diferencia de las constituyentes francesas, donde si acaso alguna vez se menciona la tradición o legislación histórica ${ }^{12}$. En España esta permanencia de la Constitución histórica, de Cortes y Rey, garantizaba la legitimidad de la obra gaditana. Espiga deja bien claro el 27 de octubre de 1811 que "la comisión ha dicho que no ofrece en su proyecto cosa alguna que no esté consignada del modo más auténtico y solemne en nuestro antiguo gobierno». El tradicionalista Borrull, al presentar la nueva propuesta de organización de un presupuesto y control del mismo por las Cortes, dice que se trata de restablecer «los derechos que se reservaron los pueblos al tiempo de formar las Monarquías de Asturias y Sobrarbe, que constan por las leyes del Reino». Es tan puntillosa la documentación de nuestros constituyentes gaditanos que dan hasta el nombre de quien (el marqués Caballero) "con notoria temeridad y abandono de sus obligaciones" hizo "borrar de la memoria de las gentes" semejante antecedente, "mandando que no se insertasen en la Novísima Recopilación, lo que no podrá suceder ahora que ha declarado V. M. (las Cortes de Cádiz) en el artículo 131 de la Constitución las facultades de las Cortes, y entre ellas la de establecer las contribuciones y aprobar el repartimiento de las mismas entre las provincias" ${ }^{13}$. El propio Flórez Estrada en su proyecto de Constitución de 1809, para justificar la necesidad de la misma, se remonta a "nuestros antepasados", empezando por el código gótico que "cuidó primeramente de dar leyes a los monarcas, de deslindar sus derechos y de prescribir sus obligaciones, aun antes que las de los súbditos" ${ }^{14}$.

12 Le comte de Lally-Tollendal -anglómano citado por Constant-, del comité de la Constitución, el 31 de agosto de 1789, defiende la balanza y equilibrio de poderes en el clásico diseño de dos Cámaras y Rey.

t3 Borrull el 11 de noviembre de 1811: Diario de Sesiones de las Cortes Generales y Extraordinarias (DSCGE).

14 Constitución para la Nación Española. Presentada a S.M. la Junta Suprema Gubernativa de España e Indias. En 1. ${ }^{\circ}$ de noviembre de 1809. Por Álvaro Flórez Estrada. Procurador General del Principado de Asturias. Introducción. El significado de "constitución gótica", "Constitución histórica", "leyes fundamentales" en Álvarez Alonso, C.: “Un Rey, una ley, una Religión (Goticismo y constitución histórica en el debate constitucional gaditano) " en Historia Constitucional. Revista Electrónica, $n .^{\circ} 1$, junio 2000. Sobre Jovellanos, Coronas GonzALEZ, S. M.: «El pensamiento Constitucional de Jovellanos", en Ibidem. 
Aún más, se busca la tradición del pensamiento español en el reconocimiento de los derechos del pueblo, sin necesidad de recurrir al pensamiento foráneo. Así lo hace Villanueva el 7 de octubre de 1811. Del mismo modo, En el discurso preliminar del 12, aludiendo al Fuero Juzgo se dice que «la soberanía de la nación está reconocida y proclamada del modo más auténtico y solemne en las leyes fundamentales de este código» ${ }^{15}$. El mismo Argüelles recurre a la tradición en la conformación y denominación de instituciones: «la Diputación es propia y peculiar de España, y no tiene ejemplo en ningún otro país en que se halla adoptado un gobierno representativo", defendiendo ese término frente al de "legislatura" "que no es española», para referirse, según explicó la propia Comisión constituyente, a una de sus acepciones posibles, en concreto a «las dos reuniones de unos mismos Diputados en los dos años de su encargo ${ }^{16}$.

Tanto deseo de mantener la tradición lleva a los constituyentes a dejar al margen de las discusiones de Cortes la religión católica y la Monarquía, principios que habia sentado Quintana en línea con el pensamiento de Jovellanos. Respecto a la Monarquía, al contrario que con la religión, eso parecía inevitable, con sólo observar lo que sucedió en el resto de países occidentales. Los propios revolucionarios franceses, en el primer momento, en su primera Constitución, no la discutieron en absoluto. Bien al contrario, la discusión se centró sobre el carácter que debia tener su intervención en el legislativo: sanción o veto ${ }^{17}$. En cuanto a la religión, no hubo en España nada parecido a la "Constitución civil del clero" de Francia, aquí pesó decisivamente su consideración de Ley Fundamental, por la influencia del "goticismo" citado que implicaba la asunción de la religión como pilar de la Monarquía y la cohesión de la sociedad. Sin embargo, a pesar del artículo 12, como veremos, se inició el camino hacia la reforma: desde la abolición de la Inquisición el 22 de febrero de 1813 , hasta la transformación de la situación económica de la Iglesia, que la hacía dependiente del Estado. De hecho, en la práctica, se buscaba la independencia Iglesia/Estado, pero la teoria, al menos de primera hora, no lo indicaba asi ${ }^{18}$. Lo cierto es que en el constitucionalismo inglés, en el americano y en el francés, se recogía la libertad religiosa, quizás la única que no recogió el Código gaditano.

15 La autoridad (el Rey) "la recibe de sus mismos súbditos. Y esta doctrina no la hemos mendigado de extranjeros; la enseñan sabios teólogos y publicistas españoles de los mejores tiempos", pp. 20102011.

16 Argüelles, Id., pp. 2013, 2007.

17 En palabras de Furet y Hálevy, eligieron entre conservar simplemente al Rey o establecer plenamente un gobierno monárquico. En realidad, la cuestión de la Monarquía fue el corazón de los debates y de las luchas hasta 1791, y es el que divide al campo revolucionario: FuRET, F.: HaLÉvy, R.: La Monarchie Républicaine. La Constitution de 1791. Fayard, 1996, pp. 13 y ss., p. 9 Debates de agosto y septiembre de 1789, centrando en ella todos los debates: APP.AN. Ciertamente perdieron los que proponian el veto absoluto, es decir, la propia comisión constituyente: Mounier, anglómano, en nombre de la comisión: 4 de septiembre, pp. 554-564.

18 Con ocasión de la composición del Consejo de Estado, Argüelles refutó la pretensión de que los Prelados eclesiásticos formaran parte del mismo: «... La religión tiene sus pastores establecidos por Dios, y hay una línea divisoria entre ella y el Estado; de manera que jamás se pueden confundir unos negocios con otros". El ceremonial para la toma de posesión del 24 de septiembre de 1810 es ilustrativo del peso de la religión: DSCGE. 


\section{EL MODELO GADITANO} tución.»

«La nación todo lo puede y las Cortes solamente lo que les permite la Consti-

Efectivamente, en Cádiz, a pesar de los trabajos de Jovellanos previos a la convocatoria de Cortes, se viene a adoptar una Constitución similar a la de 1791 francesa que, para lo que aqui tratamos, se caracteriza fundamentalmente por una separación estricta de poderes. Esto se materializa en la incompatibilidad entre secretario del Rey o empleado del Gobierno y diputado, para no extender «las facultades del Gobierno" (Zorraquín).

Respecto a la Monarquía en 1812, a pesar de reconocer a la nación la soberanía (art. 3 de la Constitución) y de haber aceptado en el mismo artículo del proyecto la facultad «de adoptar la forma de gobierno que más le convenga», no se llegó a incluir esta última parte en la Constitución. El primero en oponerse fue el «jovellanista» Aner, con la excusa de que no haría falta decir tal cosa habiendo establecido la soberanía nacional. Es en estos inicios donde hay que buscar la razón de la constante batalla en el resto del siglo por incorporar o no en los textos constitucionales la declaración de la "soberanía nacional». Pero hay que señalar el matiz que introdujo Aner al advertir que esa facultad implícita en la soberanía nacional de "establecer sus leyes fundamentales», en el caso de la forma de Gobierno «le pertenece en un caso extraordinario y de utilidad conocida». La razón es que, dice, "La Nación española ni se halla en el caso de variar la forma de gobierno, ni hablando políticamente le puede convenir otra que la que toda la Nación y V.M. solemnemente han reconocido, proclamado y jurado". Entiende, en definitiva, que es un principio que "solo un suceso extraordinario y una larga serie de años puede hacerlo posible".

\section{La sanción o el veto}

Una vez constituida la nación, y a pesar de la separación de Poderes, el Rey, que tiene la potestad ejecutiva (que implica libre separación y nombramiento de los Secretarios de Estado y del Despacho), participaría en el legislativo con el veto suspensivo ${ }^{19}$ que la mayoría de los liberales creen que no contradice en nada el principio de soberania nacional. Toreno, sin embargo, dice el 3 de septiembre de 1811 que "soy de la opinión que en ese artículo — el 15- sólo se diga "la potestad de hacer las leyes reside en las Cortes", suprimiéndose "con el Rey» -postura excepcional, opuesta a la manifestada ya desde el Trienio que sería la constante en el constitucionalismo posterior, si excluimos las Repúblicas y la Constitución actual (con variación de estilo en la Constitución de 1869). En defini-

19 Puede verse además, LARIO, A.: «La Monarquía Constitucional. Teoría y práctica política», cit., pp. 109-111, 123-124 
tiva, la intervención del Rey en el Legislativo se justificaba en la legislación y Cortes ordinarias, como recordó Muñoz Torrero.

De las Cortes gaditanas parte, ciertamente, la distinción de dos situaciones bien diferentes para la intervención de los poderes: la que corresponde a las Cortes ordinarias, en la que sí participaría el Rey con un veto suspensivo (el veto es negar la sanción el Monarca. A su vez la sanción es la denominación del acto por el cual intervine en la conformación de las leyes), y la correspondiente a las Cortes extraordinarias, las únicas capacitadas para la reforma constitucional, en la que no puede participar el Rey -en la línea de lo sostenido por los constituyentes franceses. Fueron Toreno y Argüelles, especialmente, quienes teorizaron sobre esta diferencia entre Cortes Constituyentes y ordinarias: "éstas son árbitras de hacer y variar el código civil, el criminal, etc, y sólo a aquéllas les es lícito tocar las leyes fundamentales o la Constitución, que siendo la base del edificio social, debe tener una forma más permanente y duradera». Para reformar la Constitución, las Cortes, extraordinarias, deben tener poderes especiales y amplios, o quedar determinado en la propia Constitución "cuándo, cómo y de qué manera podrán examinarse las leyes fundamentales por si conviene hacer en ellas la misma variación". Concluye diciendo que "La nación todo lo puede, y las Cortes solamente lo que les permite la Constitución que forma la Nación o una representación suya con poderes a este fin ${ }^{20}$. Es decir, Toreno apoyó el procedimiento especial del Título último, mucho más complejo que el ordinario y que, además, y muy importante, excluia al Rey del proceso. Una vez publicado en las Cortes el proyecto de revisión, «una Diputación presentará el decreto de reforma al Rey, para que le haga publicar y circular a todas las autoridades y pueblos de la Monarquía", sin poder intervenir en su contenido ${ }^{21}$.

Consecuentemente, se pasó a distinguir entre nación constituyente y constituida, como un seguro frente al poder del Rey, que sólo puede intervenir una vez constituida la nación, y en seguida se destaca que la soberanía, en esa lógica, reside en la Nación pero no en las Cortes ordinarias, que sólo tienen la potestad legislativa, «De otro modo - dice Muñoz Torrero- no sería el nuestro un Gobierno monárquico sino una democracia” (estaba pensando sin duda en la Convención y quizás en lo ya sostenido por la comisión francesa) ${ }^{22}$.

Fue una soberanía que en los momentos de creación de las Juntas se ejercía en nombre del Rey, pero que una vez reunidas las Cortes, empujadas por la excepcional situación de un Rey ausente y al que le tenian que restituir el

20 Toreno, 28 de agosto de 1811, DSCGE. Véase también, Argüelles, 22 de septiembre de 1811.

21 Sesión del 17 de enero de 1812

22 Para la diferencia entre nación constituyente y constituida: Terrero, 28 de septiembre de 1811. Muñoz Torrero el 15 de noviembre de 1811. DSCGE. Mounier en nombre de la comisión constituyente francesa habla de la diferencia entre el principio de la soberania y el ejercicio de la misma, que ya no debe ejercer la nación sino sus representantes. Entre ellos, el Rey también es delegado del pueblo: cit., pp. 560-561. Muñoz Torrero el 15 de noviembre de 1811. 
poder, éstas actuaron como la más alta instancia política de España, pues sólo tenian enfrente a un Consejo de Regencia que no podía aportar la fuerza y legitimidad del poder real. De hecho se le dio el tratamiento de Excelencia, y los Regentes cobraban un tercio menos que los Secretarios de Despacho. Desde luego no prosperó la moción de Mejía que sostenía que debían ser los Regentes la más alta autoridad, "porque siendo ellos el Poder ejecutivo, tienen la mayor confianza de la Nación». De hecho Se obliga al poder Ejecutivo a residir en el lugar del "Congreso nacional", que era el soberano y tenía tratamiento de Majestad, y «no podrán pernoctar fuera del lugar de su residencia sin conocimiento de las Cortes, y ninguno de ellos podrá ausentarse sin licencia». $Y$ es que el Decreto de 24 de septiembre estableció que el poder ejecutivo en ausencia del Rey, "serían responsables a la Nación». Por ello se produjeron constantes fricciones entre ambas instancias con diversos cambios de los Regentes por las Cortes ${ }^{23}$.

\section{La doble Cámara}

Al igual que se plantearon los constituyentes franceses, derrotados en su propuesta de doble Cámara, en España, ya desde el proceso para convocar Cortes, la cuestión era si habría doble Cámara o Cámara única. Si bien faltó un acuerdo previo (lo que suele achacarse a la falta de libertad de imprenta ${ }^{24}$ ), el propio Infantado alude a una "opinión general» a favor de una única Cámara ${ }^{25}$. En lugar del Senado, se colocó el Consejo de Estado que, en palabras de Argüelles, que creía que podía hacer sombra al legislativo, no fue ni más ni menos que una «especie de correctivo" para la Cámara de Diputados, por las mismas razones que alegaron los constituyentes franceses: la necesidad de moderar el impulso de los diputados y de legislar con prudencia y con calma. Pero este Consejo de Estado, no sólo es sustitutivo del Senado, sino que parece en algunos diputados destinado a sustituir al Consejo de Ministros que ahora se prevé. Toreno, en contra, recuerda que ya existe un Ministerio de la Gobernación, y que de las facultades del Consejo de Estado "muchas corresponden a las Cortes, y otras al nuevo Ministerio de la Gobernación; $y$ teniendo además que establecerse entre los ministros una junta, y formar

${ }^{23}$ Puede verse Flaquer Montequi, R.: «El Ejecutivo en la revolución liberal», en Las Cortes de Cádiz, n. 1 de la revista Ayer, edición de M. ARTOLA, Madrid 1991; pp 37-65.

${ }^{24}$ La libertad de imprenta decretada el 10 de noviembre de 1811, fue reconocida desde la primera hora como el único medio de ofrecer al conocimiento del Rey la situación de la sociedad, y por lo tanto, como dijera Flórez Estrada, el único medio para poder «evitar y poder reparar los males anejos a todo gobierno, mientras no se descubra uno compuesto de hombres sin pasiones": La Representación a S.M.C. el señor Don Fernando VII en defensa de las Cortes, folleto escrito en su exilio en Inglaterra tras la vuelta de Fernando VII en 1814. Publicado por primera vez en Londres, en El Español Constitucional.

${ }_{25}$ Carta del duque del Infantado a Lord Holland de 2 de agosto de 1809: se trataba de acordar primero si las Cortes se compondrían de dos Cámaras y Soberano -en alusión directa a la "admirable" Constitución inglesa-, o la representación nacional debia ser la encargada de decidir la cuestión: MoRENO ALonso, La forja del liberalismo..., cit pp. 276, 278, 313, 316. 
una especie de consejo privado, no ocurrirá tan frecuentemente consultar a ningún otro Cuerpo si por ello pide que no sea un cuerpo numeroso ${ }^{26}$.

Y es que no se concebía una Cámara alta en el contexto de lucha contra el despotismo, así se preguntaba el mismo Queipo de Llano (conde de Toreno): « ¿cómo puede imaginarse que una Cámara alta sea la que ponga freno y coto al despotismo?... La Cámara alta se ha de componer de sujetos distinguidos y privilegiados, y más bien se aunará con el Rey, el más privilegiado y favorecido de todos los individuos de la Nación „27; aunque, seguidamente, y ratificando el constante seguimiento del caso inglés, creyó necesario mencionar la distinta naturaleza y función social de la nobleza en Gran Bretaña y España. Pero en esta ocasión fueron los realistas los que más veces trajeron a colación el modelo constitucional británico en defensa de las dos Cámaras, mientras que los liberales, y especialmente Toreno mantuvo tesis estrictamente individualistas —en contra radicalmente, de nuevo, de su postura posterior ${ }^{28}$.

\section{La dualidad del Poder Ejecutivo}

Dentro del Poder Ejecutivo, fue en esta primera época constitucional cuando ya se planteó lo que era la base de la teoría del cuarto poder de Constant y que definió Bagehot de otro modo, diferenciando entre poder eficiente y dignificado: la diferencia de dos instancias en el poder Ejecutivo. Ya Argüelles habla de un «Consejo de Ministros», que también denomina «junta metódica», para en el futuro armonizar las decisiones "en los asuntos de urgencia», añorando "el acuerdo y sistema que en el día no hay" puesto que los Secretarios de Despacho no pueden ser parlamentarios - lo que no volverá a suceder en España hasta 1873-, y alude ¡cómo no! a la práctica comparada de otros países, «aunque no hay ley sobre el arreglo de los Ministerios". Otras medidas propiciaban flexibilizar la rígida separación entre los dos poderes, la unión entre los Secretarios y las Cortes para la dirección política; en ese sentido ya Argüelles tiene presente precisamente el funcionamiento parlamentario incluso en lo relativo a la responsabilidad conjunta, a la "uniformidad de principios», echando de menos precisamente que el Rey no pueda tomar de entre los Diputados los Secretarios «como hacen otras naciones, con el fin de enlazar mejor las dos autoridades». La alternativa es tomarlos del Consejo de Estado - vemos que esta institución parece destinada en este modelo a suplir todo lo que falta para que sea un sistema parlamentario: la doble Cámara y la comunicación entre el Ejecutivo y el Legislativo a través del Gobierno ${ }^{29}$.

26 Toreno el 2 de octubre de 1811: DSCGE. La posición de Alcalá Galiano respecto a este Consejo, con las desventajas del Senado y sin sus ventajas, en SÁNCHEZ, R.: cit., 152.

2713 de septiembre de 1811: DSCGE

28 El Conde de Toreno, 20 de septiembre de 1811: DSCGE. Véase de VARELA SuANZES, J.: Estudio Preliminar (La trayectoria del Conde de Toreno: del liberalismo revolucionario al liberalismo conservador) a Conde de Toreno, Discursos Parlamentarios, JGPA, Oviedo, 2003, pp. XII-XXIII.

29 Argüelles, 9 de noviembre de 1811: DSCGE, p. 2235. 
De gran importancia fue también el intento de establecer la responsabilidad política de los Secretarios ante las Cortes. Estos fueron los primeros intentos, que continuaron durante el Trienio de forma más intensa, para establecer un gobierno parlamentario; lo que no tendría éxito finalmente hasta la época que siguió a la muerte de Fernando VII. Las sucesivas destituciones de las Regencias (Giraldo el 18 de agosto de 1812 diferencia ya responsabilidad penal de la política), y el debate sobre el "Nuevo Reglamento para la Regencia del Reyno" -que rigió desde enero de 1812-, fue la ocasión para empezar a plantear la responsabilidad política de los Secretarios de Despacho y dar flexibilidad a las disposiciones constitucionales que cerraban el paso a ese gobierno parlamentario ${ }^{30}$.

Esta separación estricta se refleja también en la relación con el poder Judicial “Ni las cortes ni el Rey podrán ejercer en ningún caso las funciones judiciales, avocar causas pendientes, mandar abrir los juicios fenecidos". Sólo había un problema: la substanciación de la responsabilidad penal de los ministros (que más tarde se solucionó dando a la Cámara alta en este campo funciones jurisdiccionales), y de los propios miembros del Poder Judicial. Los legisladores gaditanos tenían más confianza en la potestad legislativa por ser, en palabras de Toreno, «la menos temible de todas (por) la remoción frecuente de sus individuos elegidos por todos los ciudadanos". Además recuerda este diputado el caso inglés, donde «los ministros y los magistrados son puestos en juicio ante la Cámara de los Pares". Argüelles lo apoyó plenamente porque no encontraba modo de pedir responsabilidad al propio Tribunal especial que se creara al efecto. Sólo la Nación a través de las Cortes sería la "única autoridad competente" "31. Así pues, igual que se desconfiaba del poder Ejecutivo, se desconfiaba del Judicial que «es un cuerpo numeroso diseminado por toda la Monarquia", a lo que hay que añadir que sus cargos son vitalicios y "sus facultades se ejercen diariamente sobre las acciones de sus ciudadanos, sobre sus propiedades, y sobre todo lo más querido...". Se acude también a la historia española y, concretamente, al caso aragonés y la solución de las "greuges" o agravios del poder, y propone un nombre parecido para el tribunal que atienda responsabilidades. Pero al no existir la Segunda Cámara, la responsabilidad quedó a cargo del Supremo Tribunal de Justicia (arts. 259-261).

3o Para un tratamiento extenso desde el Derecho Constitucional: Fernández Sarasola, Poder y libertad: Los origenes de la responsabilidad del Ejecutivo en España (1808-1823). Prólogo de J. Varela Suanzes; CEPC, Madrid 2003; sobre carácter de las sustituciones de las Regencias y el inicio de la petición de responsabilidad a los Secretarios: $370-380$.

31 DSCGE, proposición del Conde de Toreno el 21 de noviembre de 1811, p. 2306-2307, 2317. Proposición de Argüelles el 22, pp. 2315-2316, que la sustituye y el primero apoya (2317). También Toreno el 16 de noviembre, p. 2263. 


\section{LOS PRIMEROS INTENTOS DE CORREGIR LAS RELACIONES ENTRE PODERES: EL TRIENIO}

Tras el primer fracaso del liberalismo español, la aceptación del modelo constitucional a que se vio obligado Fernando VII, dio inicio a la primera práctica constitucional española con el rey en presencia, y con ella a la evidencia de las dificultades que planteaba un sistema de poderes separados y sin medio viable de comunicación y concordia; no era otra cosa lo que había sucedido en Francia bajo la Constitución de 1791. Así comenzaron los intentos de modificar este modelo constitucional y por lo tanto la propia Constitución de 1812 en un sentido de convivencia parlamentaria.

A esa corrección iba encaminada la tendencia Moderada del Trienio, los llamados doceañistas, porque provenían de las Cortes de Cádiz, como Argüelles, Martínez de la Rosa, Muñoz Torrero y Toreno. A ellos se oponían los llamados "veinteañistas", a los que podemos imaginar recién llegados en 1820 con todas las ilusiones a poner en práctica un modelo que, siendo revolucionario, había adoptado ya un carácter épico, de lucha por la libertad; enfrentarse a ese modelo debia resultar, de algún modo, un alineamiento con el propio Rey al que acababan de domeñar.

Pero una característica fundamental de esta época es que, si bien las posiciones generales iban quedando claras, las soluciones ofrecidas se nos muestran confusas. Por ejemplo, no fue definitiva la división entre Moderados y Exaltados en la cuestión de la separación de poderes. Muchos Moderados como Martínez de la Rosa ${ }^{32}$ mantuvieron una concepción rígida de la separación de poderes, defendiendo únicamente la responsabilidad penal de los ministros ante las Cortes. Por el contrario, eran más bien los Exaltados o Veinteañistas, en su afán de convertir las Cortes en el centro del Estado y de la gobernación del país, los que querían incluir la responsabilidad política de los secretarios del Despacho, pero no para organizar un sistema de gobierno parlamentario sino más bien asambleario. Consideraban que el Rey y los ministros debian limitarse a ejecutar las directrices jurídicas y políticas dadas por las Cortes, como único órgano verdaderamente representativo de la nación, confundido incluso a veces con la nación misma, como algunos diputados en Cádiz habian mantenido. Parecian caminar hacia un sistema parlamentario pero no, en absoluto, en el sentido que este tenía en la práctica inglesa y en la posterior a la muerte de Fernando VII, de moderación de la revolución, sino, al contrario, intentaban potenciar ésta. Hubo algunos que, como Toreno, tenían, por el contrario, perfectamente claro que el sistema de gobierno parlamentario pasaba por la estrecha relación y confianza de los ministros y la mayoría de las Cortes, lo que implicaba corregir esa estricta separación entre ambos poderes que dibujaba la Constitución gaditana, permitiendo a los Secretarios de Despacho sentarse en las Cortes ${ }^{33}$. 2005.

32 Puede verse Pérez de la Blanca Sales, P.: Martínez de la Rosa y sus tiempos, Ariel, Barcelon a,

${ }^{33}$ Toreno, José María Queipo de Llano Ruiz de Saravia, Conde de: Historia del levantamiento, guerra y revolución de España: Alicante: Biblioteca Virtual Miguel de Cervantes, 2003; p. 34. 
Ciertamente fue en el Trienio cuando se establecieron algunas instituciones de carácter parlamentario; es el caso del Gobierno como órgano colegiado o la preeminencia del primer ministro. Pero la parlamentarización no era posible por el ordenamiento constitucional que hacia incompatible el cargo de ministro y diputado, y la prohibición al Rey de que disolviese las Cortes; sin embargo, cada vez se ponía más de manifiesto que al menos el Ejecutivo y el Legislativo debian marchar de acuerdo en la dirección política del Estado, para que ésta fuera eficaz.

Seguramente fue esa necesidad de eficacia la que nos hace encontrar en el Trienio prácticas propias del liberalismo post-revolucionario, contrarias de hecho al modelo gaditano, del que no parecían propios ni los votos de censura, puesto que no había control político de las Cortes sobre el poder ejecutivo; ni los Mensajes de la Corona con el carácter que adquirieron de presentación parlamentaria del programa del Gobierno en las Cortes; y que se pusieron por primera vez en práctica en estos momentos.

El primer voto de censura en España se produjo el 15 de diciembre de 1821, cuando las Cortes pidieron a Fernando VII que destituyera a su Gobierno, el de Eusebio Bardají. El Rey, tras consultar al Consejo de Estado, aceptó la petición y cambió el ministerio por el de Martínez de la Rosa. Precisamente este político, junto con Toreno, representaba la política de comedimiento en el proceso constitucional, intentando incorporar el modelo parlamentario, copiado de la carta francesa y que, fundamentalmente, significaba la introducción de la Segunda Cámara. Esta cámara "elitista" venía a representar la mano tendida a las fuerzas del Antiguo Régimen, y el modo más práctico de implicarlas en el nuevo sistema liberal, en el que asi tendrian un lugar.

Este intento de reforma constitucional que recogen fuentes clásicas, según los últimos estudios nunca lo habría llegado a proponer Martínez de la Rosa por no considerarlo oportuno. Ciertamente, también existía una fuerte oposición a lo que se consideraba ceder ante la presión extranjera, abiertamente expresada por Luis XVIII en la apertura del Parlamento en 1823 y correctamente interpretada por Canning, primer ministro inglés también ante el Parlamento el 4 de abril del mismo año, reconociendo que se quería obligar a España a una reforma constitucional porque la existente no emanaba de la Corona - como se recordará al reformarse la Constitución en $1836^{34}$.

Por su parte, el denominado "discurso de la Corona", en el gobierno parlamentario, es el primer paso que da todo Gobierno formado por el Rey; con él éste presenta ante las Cortes a su Gobierno y éstas discuten y votan el programa así presentado. Es el primer control parlamentario que todo Gobierno debe pasar para comprobar si tiene apoyo suficiente para poder gobernar. Pues bien, esta práctica también se inició en el Trienio. La discusión del discurso o "Mensaje» de

34 Pérez de la Blanca: Martínez de la Rosa, ob. cit., pp. 197-201. Las presiones extranjeras para reformar la constitución de 1812, entre otros, 14 de diciembre de 1836: DSC, p. 626. 
la Corona la introdujo Toreno de modo circunstancial el 9 de julio de 1820 , y fue sancionado por el Reglamento de Cortes de 1821, a pesar de que iba en contra del modelo político de 1812, en el que se establecía una separación estricta entre los poderes: en realidad no pedía que las Cortes aprobaran los Gobiernos del Rey; en todo caso exigiría, de momento, que el Ejecutivo cumpliera fielmente los mandatos del Legislativo ${ }^{35}$.

Hay otra figura típica del modelo parlamentario que también se inició en el Trienio. Es la de la obstrucción parlamentaria. Se produjo la primera en febrero de 1822 contra el proyecto Garelli (ministro de Justicia del Gobierno moderado de Martínez de la Rosa) para limitar la actuación del Jurado en los delitos de imprenta. Este Gobierno había sido formado por el Rey para frenar la tendencia mayoritaria de la Asamblea, de signo contrario; ésta decidió obstruir la tendencia del Gobierno, que se vio así aprisionado entre las luchas del Rey y la Asamblea ${ }^{36}$.

\section{LA CORRECCIÓN PARLAMENTARIA DEL MODELO POLÍTICO ESPAÑOL. EL SEGUNDO CAMINO INGLÉS}

Los dos exilios políticos que sufrieron los liberales españoles, con ocasión de la vuelta al absolutismo por parte de Fernando VII, sirvieron para ponerlos en contacto con las tendencias políticas europeas; pero entonces ya no sólo de Inglaterra, sino también de la Francia posterior a 1814 y de Bélgica, fundamentalmente. Estas tendencias no eran otras que el gobierno parlamentario ${ }^{37} .1834$ parece el momento de volver a intentar la convocatoria de Cortes para llevar a cabo el proceso constitucional, ahora sí, de acuerdo a lo establecido y a la moderación que parecía exigir el momento ${ }^{38}$. Con la ruptura de 1836 y tras la Constitución de 1837 se avanzó decididamente en el modelo parlamentario de Gobierno, al menos en la estructura constitucional, que debería haber sido desarrollada por la práctica politica.

De hecho, en 1836, "ahora que España va a constituirse» se publican «en lengua vulgar las principales constituciones porque se gobiernan estados grandes y adelantados en la civilización", porque "no sólo es útil, sino hasta necesario, que se generalicen y conozcan»: Francia y Bélgica, «porque sobre su sencillez y puntos recomendables, son las últimamente redactadas; y encierran, particularmente

35 Es bien significativo que algunos diputados hubieran propuesto abandonar ese debate sobre el discurso de la Corona: PÉrez de la BlanCA, cit., 117.

36 Sevilla Andrés, D.: "El poder constituyente en España de 1800 a 1868 ", Revista del Instituto de Ciencias Sociales, n. ${ }^{\circ}$, Barcelona 1964. Id. Del 19 de marzo al 14 de abril (ensayos), Valencia 1959. ARTOLA, La España de Fernando VII, cit., pp. 30-32, 565 y ss.

37 Para Alcalá Galiano y la influencia del exilio en su ideario, SÁnchEZ, R.: cit., cap. 3: «Desde la perspectiva del exilio". Puede verse A. LARIO, «La Monarquía Constitucional. Teoría y práctica política», cit., pp. 112 y ss.

38 Sobre el inicio de las diferentes prácticas parlamentarias durante el Estatuto, escribi en «El modelo liberal español ", Revista de Estudios Políticos, n.¹22, 2003. 
la belga, precauciones muy estudiadas para evitar los abusos del poder real, y la confusión de los del estado». Portugal y Brasil, porque "sobre no ser tampoco antiguas, se han dado a pueblos más en armonía con el nuestro, o de costumbres y hábitos menos desemejantes». Estados Unidos de Norteamérica, «hemos tenido presente que era para una república federal, para un país nuevamente constituido; pero estas mismas circunstancias, a más de otras razones, convidan a darle cabida en la colección, para que formando contraste y puntos de comparación, tenga mejores datos el discernimiento". Se añade la de 1812 y su discurso preliminar, porque «esta es la única que se redactó por españoles eminentes, en circunstancias honrosas: es la única calcada sobre nuestros antiguos fueros; y por reformas que haya menester, siempre será el grande arsenal a donde nuestros representantes acudan para formar el nuevo monumento de la libertad española» ${ }^{39}$.

Una de las primeras justificaciones de la reforma fue «las circunstancias extraordinarias de aquella época, de cuyo influjo tendría necesariamente que resentirse la Constitución " ${ }^{40}$, admitiendo que no estuvo ocho años en vigor como exigía el artículo 373 antes de ser reformada, pero justificable también «por las vicisitudes por que ha pasado este Código en tan largo periodo", que dio tiempo a formarse una opinión nacional favorable a su reforma «en los puntos más esenciales con admirable uniformidad/... no sólo con los buenos principios del derecho público, sino con los más acreditados por la experiencia de otros paises».

En 1837 sale adelante la propuesta de Vicente Sancho de bicameralismo, pues al decir de Marichal dominaba la Comisión constituyente por su fuerte personalidad y enorme erudición en cuestiones de práctica parlamentaria. Sin embargo la comisión tenía liberales de tanto peso como Argüelles, que era el presidente, y Olózaga que era el secretario y que, según Tomás Villarroya fue el redactor del texto ${ }^{41}$. Su lema era: un Rey, una Asamblea y un Senado igualmente fuertes. Hay que destacar que de los diputados constituyentes en 1836 sólo cinco habian estado en la de 1812.

Las bases para la reforma de la Constitución del 12, y que se presentaron a las Cortes el 30 de noviembre de 1836, fueron:

1. eliminación de lo que podia pasar a Leyes Orgánicas y Reglamentos para presentar «bajo formas muy sencillas, el cuadro completo de un gobierno representativo". Que se aceptó sin discusión.

39 Imprenta del «Eco del Comercio», Madrid 1836.

40 DSC, 30 de noviembre de 1836, Dictamen de la Comisión de Constitución: apéndice primero.

41 MARICHAL, C.: La Revolución liberal y los primeros partidos politicos en España, 1834-1844, pp. 138-139. TOMÁs VILLARRoya, F.: "Las reformas de la Constitución de 1812 en 1836 ", en R.I.E.S., n. ${ }^{\circ} 4$, Barcelona, 1964: Olózaga el secretario, habria sido el brillante portavoz de los progresistas, fundamental papel en este pacto; desde los Moderados, y fuera del Parlamento, ese papel fue para Borrego (director de EI Correo Nacional): OLIVA MARRO-LOPEZ, Andrés Borrego y la política española del siglo XIX, Instituto de Estudios Políticos, Madrid 1959. 
2. Admisión del Bicameralismo, "mecanismo" o "máquina prodigiosa" para garantizar la verdadera representación de la opinión pública, «norte y móvil único del Gobierno" en "los sistemas representativos", y que es "tan difícil de averiguar». Ocasionó un interesante debate, aunque fue aprobado por 126 votos contra 11.

3. Robustecimiento de los poderes de la Corona en cuanto a la sanción de las leyes y la facultad de convocar, suspender y disolver las Cortes. Correspondió al artículo 44, que también dio lugar a amplia discusión.

4. Elección directa, aunque, dice Argüelles «no hará empeño la comisión en incluirla como base", y reelección indefinida.

La discusión comienza desde la propia comisión, donde hay una minoria que, deseosa de mantener la Constitución de 1812, pide que para aprobar cualquier reforma se requiera los $2 / 3$ de los votos y no la mayoría simple como quiere la mayoría de la comisión. Esa minoría pone como ejemplo, por boca de Alonso, la Constitución belga "obra exclusiva de los franceses» pero "con calma y reflexión», y la Constitución de Estados Unidos, "pueblo más ilustrado y feliz", además de la propia Constitución del 12. Pero la mayoría estaba dispuesta a hacer una nueva Constitución. En esta discusión se acabó con cualquier idea de reforma, en la que se apoyaba la minoría, para dar por sentado que las Cortes habían sido reunidas para este objeto, es decir, eran Constituyentes, y no requerian ninguna mayoría especial.

\section{La sanción}

La idea de los $2 / 3$ necesarios que pedía la minoría iba dirigido expresamente al veto regio, pues se creía que no los obtendría para acabar con el meramente suspensivo de Cádiz; es decir, a frustrar el intento de fortalecer los poderes de la Corona, que era una base de la reforma constitucional. La primera oposición frente a este intento vino de Pascual y su negativa a darle más latitud a la «autoridad Real» "por más respetable que sea para mí». En cambio, pide la responsabilidad "contra la arbitrariedad de los que en su nombre ejercen el poder", como si ya previera - estamos en una Regencia- quiénes eran los interesados en fortalecer el poder regio. Uno de los argumentos fuertes para oponerse fue la misma existencia de dos cuerpos colegisladores, que haría innecesario, dicen, la sanción del Rey. En todo caso, se pide que, al menos, «sea con limitación, porque lo contrario sería abrir la puerta a la tiranía y al poder arbitrario si se le concediese el veto absoluto". También pide limitaciones en «las facultades de convocar y disolver las Cortes. ¿Qué necesidad tenemos de arreglar esta parte de nuestra Constitución con la experiencia adquirida?... ¿Permitiremos que la representación nacional quede expuesta a los golpes de la tiranía? Siendo así, un mal Gobierno triunfaría de la voluntad nacional...". Por el contrario sostiene que "nuestra Constitución debe fijar los periodos de convocar y disolver las Cortes; una comisión compuesta 
de individuos de ambos Cuerpos debe convocar a las Cortes con acuerdo del Gobierno, y de esta manera se impedirá que haya arbitrariedad"42. Por el contrario, los argumentos a favor de la intervención del Rey en la vida de las Cortes, se apoyaban esencialmente en que la reunión anual de éstas estaba garantizada por la necesidad práctica y constitucional de aprobarse en ellas los presupuestos, evitándose así la tiranía.

Es en esta discusión cuando quedan definidos el poder Real y el Ministerial «o Ejecutivo", que se asegura estar ya diferenciado en las bases de reforma. Es la materialización de la teoría de Constant del Poder Moderador, con un espacio de poder del que nadie sería responsable, y con sólo una "responsabilidad moral»; lo que con el tiempo se irá matizando, hasta no dejar nada fuera de la responsabilidad ministeria| ${ }^{43}$. El Rey se presenta como cuerpo colegislativo (recordemos «EI Rey en Parlamento» inglés), siéndole entonces fundamental el veto, que le viene a igualar a las dos Cámaras: "tres poderes iguales o independientes", sobre todo para que el Poder Ejecutivo no se viera forzado a ejecutar lo que no creyera conveniente, sin posibilidad de intervención. Lo que resulta extraordinariamente débil es la argumentación de la Comisión para reformar el artículo 149 de la Constitución gaditana que ponía ya bastantes reparos a la entrada en vigor de una ley no aprobada por el Rey. Según ese artículo, éste la podía denegar dos veces consecutivas - sólo se podía tratar en las Cortes el mismo asunto una vez al año-, hasta que la tercera vez que las Cortes aprobaran el mismo texto, pasaba a ser ley. Pero como eran justamente dos años lo que duraba un mandato parlamentario, la tercera vez y definitiva en que la sanción era automática, correspondia a nuevas Cortes que deberian aprobar nuevamente el proyecto en cuestión. La Comisión alegaba que "es en extremo improbable que en un Gobierno constitucional se resista el Rey a sancionar una ley que la Nación desee". Una vez más queda de manifiesto la tendencia a dejar a la práctica política como garante del gobierno constitucional; pero el argumento, en este caso, no podía ser más endeble, sobre todo porque los medios que dicen tener la opinión para contrarrestar los actos del Rey, en el caso español no fueron tales, controladas como estaban las elecciones. De hecho ya se habian producido unas elecciones directas que ocasionaron la denuncia del influjo gubernamental.

\section{La posibilidad de la disolución}

"Medida grave que debe usar el Gobierno con extremada parsimonia", según la Comisión, se justifica por «la necesidad de poner en armonía los Cuerpos Colegisladores entre sí o con el poder Ejecutivo"; en este último caso, cuando el Rey mantenga la confianza en los ministros y éstos no tengan mayorías parlamentarias,

42 Pascual, 15 de diciembre de 1836, DSC, 629.

4315 de diciembre de 1836 , DSC. $639-640$ 
podrán acudir a la opinión pública; a su vez, puede percibir el Rey si se ha equivocado en su apoyo al Ministerio: nunca como en esta ocasión el Rey está ejerciendo de Moderador, de balanza, de árbitro que hace mover las cuerdas de los poderes para que éstos entren en acción; decía la comisión que «es la única (medida) que en ciertas circunstancias puede salvar al Estado pacíficamente " ${ }^{44}$. La figura de la disolución, de tanta importancia en la práctica política parlamentaria, ya desde el Estatuto tenía el sentido de apelar a la nación, según lo recoge su Preámbulo. Era la idea de Martínez de la Rosa cuando decía que los pueblos son el último Tribunal de Apelación. La primera disolución de nuestra historia constitucional se produjo el 26 de enero de 1836 por el Gobierno Mendizábal. A partir de ahí, toda la malformación de la práctica política se basó en esta prerrogativa, al funcionar paralelamente al control de las elecciones por los Gobiernos. Quizá sea el discurso de Dionisio Valdés de 13 de diciembre el que mejor nos resuma la mentalidad de la reforma: muestra primero la definitiva influencia del Trienio sobre la decisión de reformar, de cambiar el modelo de Asamblea por el Parlamentario, y segundo la confianza en el correcto funcionamiento parlamentario, porque siempre que los ciudadanos elijan a los representantes que quieran no habría ningún peligro. Pero muestra, sobre todo, un acto que podriamos calificar de impotencia ante las circunstancias: «este pequeño sacrificio de reformar la Constitución, si es que lo sea, porque apoyado en la conveniencia pública, juzgo que es muy útil. No se considere esto como una humillación, sino como un acto de conveniencia propia". De hecho, ya se había practicado la disolución, y como recuerda Montoya, «entre nosotros la experiencia es muy reciente, pues que en un año se ha disuelto por dos veces las Cámaras, y la última con estrépito contra los que hicimos oposición al Ministerio s ${ }^{45}$.

\section{El Bicameralismo}

Para apoyar el bicameralismo, justificado por la necesidad de que «ni una sola vez pueda equivocarse la manifestación de esa opinión", para lo que es preferible «deliberar separadamente» y cuya utilidad es «demostrada por la experiencia y confirmada por la opinión general» ${ }^{46}$, se acudió incluso al Trienio y a la caída en 1823 del sistema liberal: «era necesario quitar todo pretexto a nuestros enemigos y reformar la Constitución". En aquel momento no fue posible por no pasar a depender de gabinetes extranjeros, aparte de que "ahora es mucho más fácil proceder a la reforma de la Constitución, porque no hay la discordancia de opiniones en este punto». Argüelles dijo que "Creo que en el dia la verdadera opinión de España está a favor de los Cuerpos Colegisladores», reconociendo que fue el caballo de batalla en 1822 y 1823: «sobre esta división giró la mayor parte de la guerra clandestina que se hizo entonces a la Constitución", siendo abandonada

44 Dictamen de la Comisión de Constitución: DSC, 30 de noviembre de 1836, apéndice primero.

45 Montoya el 13 de diciembre de 1836: DSC, p. 617.

46 DSC, 30 de noviembre de 1836, dictamen de la comisión de Constitución. Apéndice 1. 
"por un gran número de personas porque no establecía dos Cámaras"; y dice más, «Todos los extranjeros pusieron el mayor empeño del mundo contra ella por no establecer dos Cámaras, y éste fue el verdadero autor de todas las desgracias en el año $1823{ }^{47}$. Lo que nos viene a confirmar las fuertes presiones, internas y externas, existentes en ese sentido durante el Trienio.

Abiertamente el segundo Cuerpo, el Senado, además de "depurar con el otro cuál es la verdadera opinión nacional», debía "contener su empuje», dice abiertamente la Comisión -imbuida de los rápidos cambios en las teorías, como reconoce y de la «impaciencia con que buscan una perfección ideal», mostrando el temor al excesivo movimiento: «impedir que se precipite»--, o en palabras de Argüelles, tener "el carácter y naturaleza de revisor» de la Cámara de los Diputados «porque por su naturaleza está expuesto a tomar con demasiado calor o precipitación algún negocio, y a otros defectos que son consiguientes a una Asamblea única». La Comisión deja de manos de las Cortes el carácter de la segunda Cámara que, aunque ha de ser diferente a la primera -calidades personales, duración del encargo, forma de nombramiento-, considera que no debe ser hereditaria como en otros países; la razón primera es «el instinto de igualdad, desarrollado prodigiosamente en España», alega la comisión. Pero, sobre todo, se entiende que si se excluye el principio hereditario y con él «queda abolido todo privilegio", en palabras de Argüelles, se amenguará la oposición que se plantea a la segunda Cámara, representada en primer lugar por Montoya que impugnó de frente las bases de reforma - excepto la primera. Finalmente es constante la justificación de que esta reforma es «lo más arreglada al Estado de nuestra Nación».

Las atribuciones de ambas Cámaras deben ser iguales, excepto «en cuanto a las leyes sobre contribuciones y crédito público", en las que predomina abiertamente la primera Cámara ${ }^{48}$. Es precisamente, en el carácter anual de los presupuestos, en el que fiaban la necesaria reunión anual de las Cortes, sosteniendo así la fuerza de la práctica política sobre las cambiantes teorías: "Este es uno de los artículos más esenciales de la Constitución, y la más segura garantía de su observancia». En la asunción o no de esta práctica parlamentaria básica, hay que distinguir las políticas constitucionales de las que no lo son en el reinado de Isabel II, cuyo extremo anticonstitucional está marcado por el intento de Bravo Murillo de un presupuesto permanente, pero que tiene sus antecedentes en la postura de ciertos sectores del partido Moderado, tan pronto como 1839 en el Gobierno de Pérez de Castro, que deben ser calificados, asimismo por ello de anticonstitucionales ${ }^{49}$.

47 Argüelles, 14 de diciembre de 1836, DSC, 627, 629. En el mismo sentido respecto al Trienio, Dionisio Valdés, el 13 de diciembre: en 1823 no nos vencieron los franceses sino los «liberales impuros o tímidos" que creían que las reformas eran concesiones al enemigo.

${ }^{48}$ Las palabras de la comisión en el dictamen citado. Argüelles el 14 de diciembre, cit.

49 Véase BURDIEL, I.: Isabel II, Espasa Calpe, Madrid 2004, especialmente la figura de Donoso y González Bravo. MARCUELLO, I.: La práctica parlamentaria en el reinado de Isabel II. Congreso de los Diputados, Madrid 1986. Especialmente Capítulo 4.: El Gobierno y los presupuestos Generales del Estado; pp. 135 y ss. y 307-308. Sostengo esto en "El Liberalismo post-revolucionario y la Monarquía de Isabel II. Una necesaria renovación historiográfica, en Ayer, 2005. 


\section{La elección directa}

El fin del sufragio universal indirecto se justificó, una vez más, por el derecho comparado, citándose a menudo la Constitución belga. Además se considera "base única y la verdadera expresión de la voluntad nacional», alegando que la elección indirecta en cuatro grados, desde la parroquia, del sistema gaditano, es una ficción -que es como se denominará precisamente andando el tiempo a las elecciones en España bajo el sistema directo. De hecho, ya se había producido una elección bajo este nuevo sistema, y ya se había denunciado — por Montoyael influjo del Gobierno en la misma; se achaca, en todo caso, a defecto de ese Gobierno. El mismo diputado expuso claramente que la elección directa y censitaria adelantaba los medios de control por la Administración y el cacique: «el Gobierno,... que tiene a su disposición la fuerza y la facultad de dar y quitar empleos, será el único que tenga influencia» ${ }^{50}$. Pero la Comisión dice algo más a favor de la elección directa, y que nos da la clave de su importancia en el liberalismo postrrevolucionario: "Tiene además la ventaja de que por mucho que se extienda el derecho de elegir, no puede extenderse fácilmente a ciertas clases, que no sabrían apreciar su importancia y que abusarían de su ejercicio", exponiendo asi abiertamente el temor a la democracia, que denunció el diputado González Alonso, a lo que consideraron proyecto democrático del 12: "serene los ánimos de los que creían que los españoles que amamos la Constitución, éramos unos demagogos furiosos, unos demócratas que no conocíamos las bases de una Monarquía templada»51. Al lado de la elección directa viene la no limitación de reelección de los Diputados.

\section{Compatibilidad de Ministro y parlamentario}

Curiosamente, sin que haya aparecido en las bases de reforma, la Comisión propone, como al hilo de las sucesivas transformaciones, algo que, sin embargo, es básico en el nuevo modelo político: la compatibilidad de Ministro y parlamentario, reconociendo que "en esto ha anticipado ya el Congreso su respetable opinión, que le servirá de norma». Una vez más, la práctica contrastada se impone a cualquier teoría, lo que lleva a la Comisión a no insistir más sobre el asunto «porque cuando la práctica sanciona constantemente la utilidad de ciertas instituciones, no sería cuerdo ni patriótico exponer a la Nación a los experimentos arriesgados de no probadas teorías».

\section{CONCLUSIÓN}

En definitiva, España transita desde el liberalismo revolucionario al liberalismo moderado de gobierno parlamentario, al pleno estilo europeo de la época. El mo-

50 DSC, Dictamen citado de la Comisión de 30 de noviembre de 1836. Montoya, 13, 14 Y 15 de diciembre de 1836, 618, 626 y ss, 640 .

${ }^{51}$ DSC, González Alonso, 3 de diciembre de 1836, p. 611. 
delo de 1812 fue el revolucionario, con separación estricta de poderes, al modo puramente constitucional que había establecido Locke y que habia introducido Montesquieu en el Continente, y que había tenido su reflejo práctico en 1791 en Francia y en la Constitución de Estados Unidos. Esta separación estricta de poderes sólo funcionó en Estados Unidos, con los poderes igualados en su origen y legitimidad -la elección popular-. No funcionó, sin embargo, en la Monarquia, donde el Ejecutivo y el Legislativo tienen legitimidades diferentes -como se demostró en 1793 en Francia o en 1820-1823 en España-. Por eso, también en España, a la muerte de Fernando VII, se corrigió el modelo en sentido parlamentario, dando lugar al que denominamos modelo post-revolucionario, de adaptación de la Monarquía al Liberalismo, a la par que aquélla servía para moderar éste. $Y$ es que la necesidad de fortalecer el poder Ejecutivo, que en una Monarquía era permanente, para garantizar el triunfo liberal y salir del proceso revolucionario, hizo volver la vista hacia la práctica inglesa, que había convertido a los Secretarios del Rey en un órgano de poder efectivo, el Gabinete, la parte electiva del Ejecutivo que sí se podía fortalecer, puesto que salía del propio Parlamento. Si no se podia fortalecer el poder directo del Rey porque corría peligro la vida de las Cortes y el propio sistema, se fortalecía el de sus ministros que actuaban como gobierno responsable ante esas mismas Cortes. Ése fue el sentido de la originalmente denominada reforma y realmente nueva Constitución de 1837, y, mucho más descarada y torpemente, de la de 1845. Mientras aquélla se produjo bajo consenso de Moderados y Progresistas, ésta fue una Constitución de partido que ejemplificó el fracaso final y la caída de Isabel II, pues el excesivo poder del Ejecutivo se hizo en nombre del Rey y en beneficio del Partido Moderado que, finalmente, acabó perdiendo también su esfera de poder ante la deriva anticonstitucional de los últimos años del reinado. 